MaPan : Jurnal Matematika dan Pembelajaran

p-ISSN: 2354-6883 ; e-ISSN: 2581-172X

Volume 7 No 1, June 2019 (32-40)

DOI: https://doi.org/10.24252/mapan.2019v7n1a3

\title{
ETNOMATEMATIKA PERMAINAN KELERENG
}

\author{
Chatarina Febriyanti1), Gita Kencanawaty2), Ari Irawan ${ }^{3}$ \\ 1,2,3Program Studi Informatika, Universitas Indraprasta PGRI \\ 1,2,3Jl. Raya Tengah No.80, RT.6/RW.1, Gedong, Ps. Rebo, Jakarta Timur, DKI Jakarta \\ E-mail: chatarina022@gmail.com ${ }^{1}$, gitakencanaway@gmail.com ${ }^{2}$, \\ ari_irawan@unindar.ac.id $\left.{ }^{3}\right)$
}

Submitted: 16-04-2019, Revised: 21-05-2019, Accepted: 03-06-2019

\begin{abstract}
Abstrak:
Tujuan dari penelitian ini adalah untuk mengungkap bagaimana permainan tradisional kelereng dapat digunakan sebagai media dalam pembelajaran matematika. Kelereng merupakan permainan tradisional, maka tujuan lain dari penelitian ini adalah untuk mengungkap unsur etnomatematika dalam permainan tersebut. Metode penelitian ini adalah etnografi, dalam hal ini peneliti melakukan pengamatan dan wawancara serta studi literatur yang berkaitan dengan permainan kelereng. Jenis penelitian ini adalah kualitatif dengan mendeskripsikan bagaimana proses permainan dan manfaat dalam permainan kelereng. Hasil dari penelitian ini adalah dalam permainan kelereng dapat melatih keterampilan motorik, melatih kemampuan berpikir (kognitif), kemampuan berhitung, mengasah keterampilan sosial, dan melatih anak mengendalikan emosi.
\end{abstract}

Kata Kunci: Etnomatematika, Tradisional, Kelereng

\section{ETHNOMATHEMATICS OF KELERENG (MARBELS GAME)}

\begin{abstract}
:
The purpose of this research was to uncover how traditional game named kelerang could be used as Mathematical learning instrument. Because Kelereng is traditional game, the other goal of this study was to find its ethnomathematic elements. The research was ethnography where the researcher conducted observation, interview, and study literature related to Kelereng game. This research used qualitative approach which described how to play the game and its benefit. The result of this research indicated that Kelereng could train motor skills, capacity to think (cognition), computation capabilities, social skills, and control emotion.
\end{abstract}

Keywords: Etnomatematika, Traditional, Marbles

How to cite: Febriyanti, C., Kencanawaty, G., \& Irawan, A. (2019). Etnomatematika Permainan Kelereng. MaPan : Jurnal Matematika dan Pembelajaran, 7(1), 32-41.

\section{PENDAHULUAN}

Etnomatematika memiliki pengertian yang lebih luas dari hanya sekedar etno (etnis) atau suku. Jika ditinjau dari sudut pandang riset maka 
etnomatematika didefinisikan sebagai antropologi budaya (cultural antropology of mathematics) dari matematika dan pendidikan matematika (Tandililing, 2013). Budaya yang di dalamnya terdapat unsur matematika maka akan lebih dikenal sebagai etnomatematika. Perkembangan dan sejarah etnomatematika di Indonesia sangat berkembang pesat karena sudah banyak penelitian yang berkaitan dengan hal ini.

Matematika sering dianggap tidak lebih dari sekedar berhitung, bermain dengan rumus dan angka-angka yang membuat pusing siswa. Sebagian besar siswa menganggap matematika sebagai pelajaran yang sukar dan menakutkan, sehingga menjadi momok bagi siswa. Hal tersebut sebenarnya bertolak belakang dengan keadaan sebenarnya. Matematika dijadikan tolok ukur kelulusan siswa (SMP dan SMA) melalui diujikannya matematika dalam ujian nasional dan diajarkan di semua jenjang pendidikan dan jurusan. Akan lebih baik jika sejak dini anak-anak diperkenalkan matematika sebagai pelajaran yang mudah dan menyenangkan (Arindiono \& Ramaadhani, 2013). Matematika ini juga sebagai dasar perkembangan ilmu, sehingga perlu dikupas lebih dalam bagaimana budaya yang ada di masyarakat sebagai bagian dari pembelajaran matematika dan dikenalkan dengan matematika realistik. Pernyataan tersebut mengemukakan bahwa matematika dalam pembelajaran etnomatematika merupakan suatu produk atau hasil karya dari suatu budaya yang dihasilkan oleh manusia dalam kehidupannya, sehingga matematika memiliki nilai-nilai sosial dan terikat dengan budaya setempat (Supriadi, Srisetyawan, \& Tiurlina, 2016). Pembelajaran matematika sangat perlu memberikan muatan/menjembatani matematika dengan kehidupan sehari-hari yang berbasis pada budaya lokal dengan matematika sekolah. Dengan asumsi bahwa etnomatematika yang diangkat sudah dikenal dan dapat membantu peserta didik dalam belajar matematika (Abi, 2016).

The study reported here is an attempt to explore how ethnomathematical studies may be implemented is an attempt to explore how ethnomathematical studies may be implemented in the context of the mathematics classroom and how related challenges may in the context of the mathematics classroom and how related challenges may be dealt with (Nkopodi \& Mosimege, 2009). Begitu banyak budaya yang dapat dimanfaatkan sebagai bagian dari pembelajaran khususnya kaitannya dengan etnomatematika. Permainan tradisional bermanfaat bagi tumbuh kembang anak, namun tidak banyak orang tua yang mengetahui manfaat tersebut, bahkan orang tua sangat jarang masih mengingat bagaimana memainkannya dan jarang menceritakan permainan tradisional yang pernah dimainkan dulu 
kepada anak-anaknya. Hal ini tentu membuat eksistensi permainan tradisional semakin tidak diketahui oleh masyarakat luas (Saputra \& Ekawati, 2017). Dalam penelitian ini, peneliti lebih fokus kepada permainan tradisional kelereng pada masyarakat di Jawa Barat.

\section{METODE PENELITIAN}

Metode penelitian ini adalah etnografi, dalam hal ini peneliti melakukan pengamatan dan wawancara serta studi literatur yang berkaitan dengan permainan kelereng. Jenis penelitian ini adalah kualitatif dengan mendeskripsikan bagaimana proses permainan dan manfaat dalam permainan kelereng. In the other than, this research uses the ethnographic approach as a research approach (Risdiyanti \& Prahmana, 2017). Instrumen yang digunakan dalam penelitian berupa panduan format wawancara, dokumentasi, dan catatan harian penelitian yang kami gunakan pada saat observasi.

Instrumen penelitian berupa panduan wawancara langsung kepada para pemain, ahli etnomatematika dan juga beberapa studi literatur dalam mengkaji legih dalam tentang permainan kelereng dan mengungkap unsur matematika apa saja yang terkandung dalam permainan kelereng. Pengamatan dan terjun langsung dalam permainan kelereng ini penulis lakukan karena penulis sendiri sudah terbiasa memainkan permainan ini sejak masih kecil sehingga akan lebih mudah bagi penulis mendeskripsikan tahap-tahap, aturan dalam permainannya dan mengupas unsur etnomatematika yang terkait dengan permainan kelereng tersebut.

\section{HASIL PENELITIAN DAN PEMBAHASAN}

Permainan kelereng termasuk salah satu permainan rakyat yang sangat populer. Kelereng terbuat dari adonan semen dan kapur bentuknya yang bulat sebesar ibu jari kaki atau terbuat dari batu wali yang dibentuk sedemikian rupa sehingga menyerupai kelereng yang sebenarnya. Permainan ini sangat membutuhkan keahlian (Hasanah, 2016). Permainan kelereng dari satu daerah dengan daerah lain memiliki penyebutan yang berbeda antara lain, tale, gundu, neyker, pincian, setein, dan lain sebagainya. Oleh karena itu, peneliti menggunakan kelereng sebagai kata yang dipilih dalam penelitian ini. Bentuk kelereng sendiri seperti bola kecil yang memiliki diameter kira-kira 1,25 cm dan memiliki berat sekitar 10 gram, terkadang di dalam kelereng terdapat hiasan berupa warna ataupun polos, seperti pada gambar berikut. 


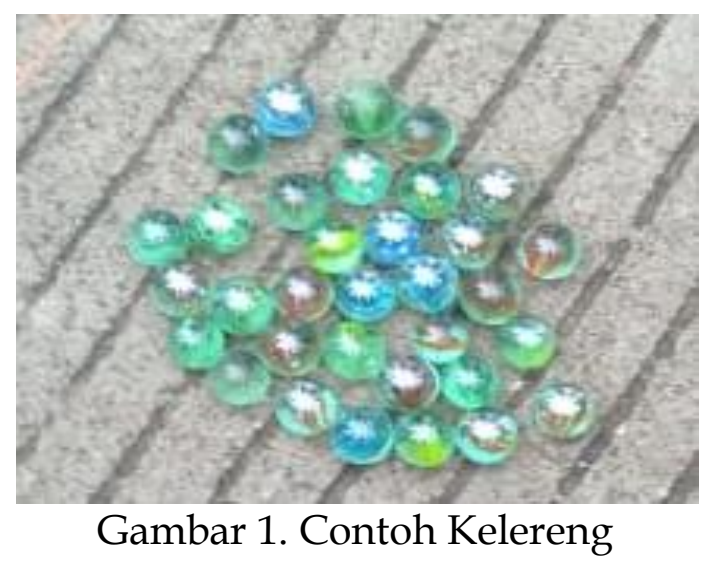

Bentuk kelereng sudah terdapat unsur matematika yaitu berupa bangun dimensi tiga berupa bola dengan memperhatikan volume, berat, diameter, dan jari-jari. Kelereng ini dapat digunakan sebagai media dalam pembelajaran bangun ruang yaitu bola dan setengah bola sebagai bagian dari pembelajaran matematika realistik. Adapun unsur etnomatematika dalam permainan kelereng dapat dilihat pada tabel berikut.

Tabel 1. Usur Etnomatematika dalam Permainan Kelereng

\begin{tabular}{|c|c|}
\hline \multirow[t]{2}{*}{ Kelereng } & Digunakan sebagai contoh media pembelajaran bangun ruang bola \\
\hline & $\begin{array}{l}\text { Sebagai alat bantu media pembelajaran operasi hitung seperti } \\
\text { penjumlahan, pengurangan, pembagian dan perkalian dengan } \\
\text { menggunakan media kelereng }\end{array}$ \\
\hline \multirow[t]{2}{*}{$\begin{array}{l}\text { Arena } \\
\text { permainan }\end{array}$} & $\begin{array}{l}\text { Pada arena permainan pasangan/ taruhan menggunakan lingkaran } \\
\text { maka dapat digunakan sebagai materi contoh bangun datar berupa } \\
\text { lingkaran }\end{array}$ \\
\hline & $\begin{array}{l}\text { Garis batas dalam melakukan pelemparan gacoan kelereng } \\
\text { digunakan sebagai menghitung jarak antara lingkaran taruhan } \\
\text { kelereng dengan batas pelemparan kelereng gacoan. Maka dalam } \\
\text { kegiatan ini, anak melakukan kegiatan pengukuran begitu pun } \\
\text { dengan lingkaran pasangan disesuaikan dengan banyaknya } \\
\text { pasangan yang terkumpul maka semakin banyak kelereng } \\
\text { pasangan maka akan semakin besar lingkaran begitu pun } \\
\text { sebaliknya. Kegiatan tersebut tanpa disadari terdapat kegiatan } \\
\text { pengukuran, akan tetapi masih belum akurat karena tidak } \\
\text { menggunakan alat ukur }\end{array}$ \\
\hline $\begin{array}{l}\text { Menyentil } \\
\text { Gacoan }\end{array}$ & $\begin{array}{l}\text { Kegiatan ini melatih konsentrasi anak dan merupakan gerakan } \\
\text { motorik halus }\end{array}$ \\
\hline $\begin{array}{l}\text { Pendidikan } \\
\text { Karakter }\end{array}$ & $\begin{array}{l}\text { Permainan ini melatih anak dalam menjunjung kebersamaan, } \\
\text { sportivitas dan kegiatan yang mengajarkan tentang nilai-nilai } \\
\text { bahwa permainan ini berguna bagi diri anak dalam bersosialisasi } \\
\text { dan bekerja sama. }\end{array}$ \\
\hline
\end{tabular}


Tempat bermain kelereng biasanya lapangan dan diperlukan gambar lingkaran di tanah atau aspal sebagai tempat untuk mengumpulkan kelereng hasil pasangan masing-masing dari peserta permainan. Dalam penyiapan tempat permainan sudah terdapat unsur etnomatematika berupa bangun datar, yakni lingkaran. Besar atau kecil lingkaran tergantung dari banyaknya kelereng yang dikumpulkan oleh peserta. Semakin banyak jumlah kelereng yang terkumpul maka lingkaran yang dibuat semakin besar, akan tetapi semakin sedikit jumlah kelereng yang terkumpul, maka semakin kecil lingkaran yang digunakan dalam permainan kelereng.

Tahapan persiapan dalam permainan kelereng antara lain: (1) permainan biasanya melibatkan 3 - 5 anak atau bahkan lebih, (2) menyiapkan lima butir gundu untuk masing-masing anak atau tergantung kesepakatan dari para pemain, (3) tanah berpasir untuk tempat bermain atau lapangan yang agak rata dan tidak menurun. Hal ini dimaksudkan agar permainan dapat dilakukan dengan baik serta meminimalisir faktor-faktor yang membuat permainan menjadi tidak kondusif. Cara bermain kelereng dapat dilihat pada gambar berikut.

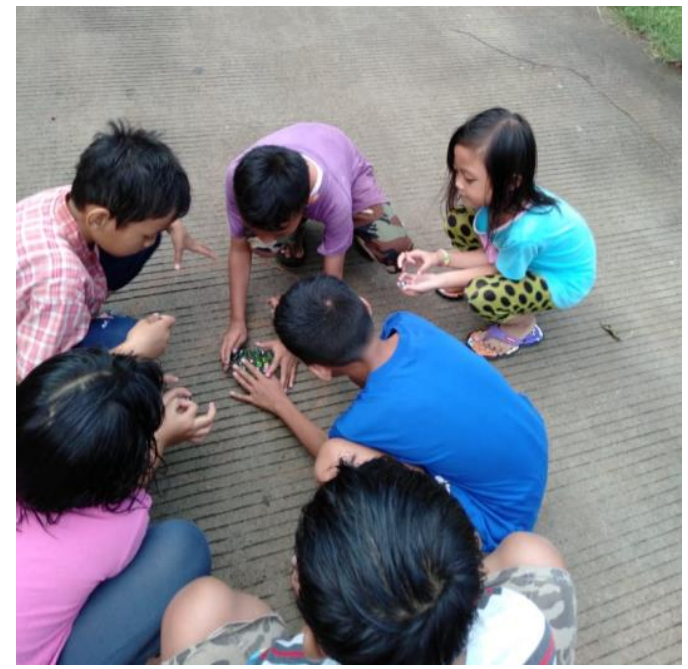

Gambar 2. Melakukan Persiapan dan Memasang Taruhan yang Disepakati di dalam Lingkaran 


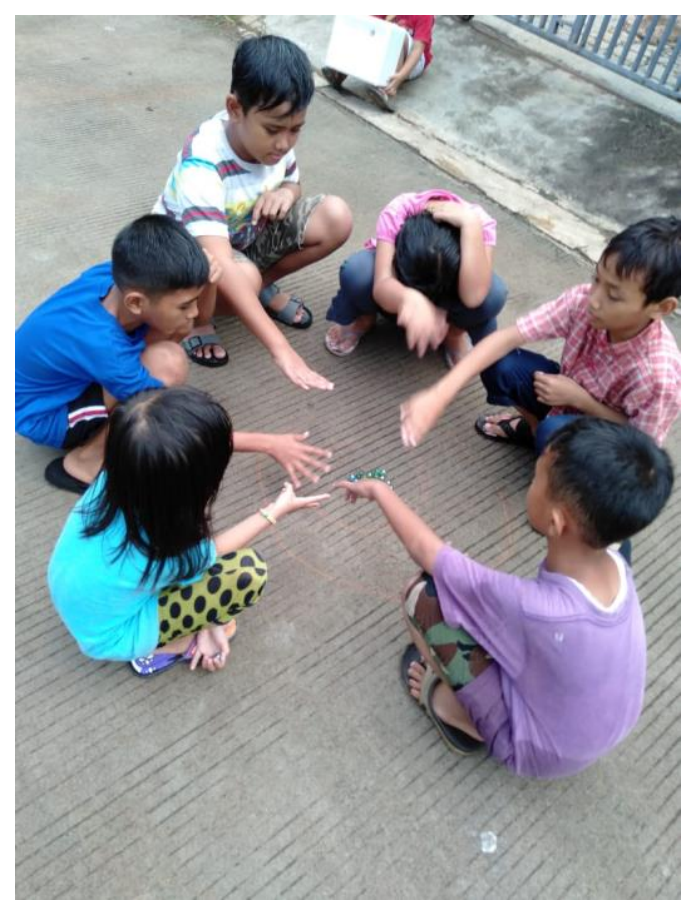

Gambar 3. Melakukan "Hompimpa” (Pengundian)

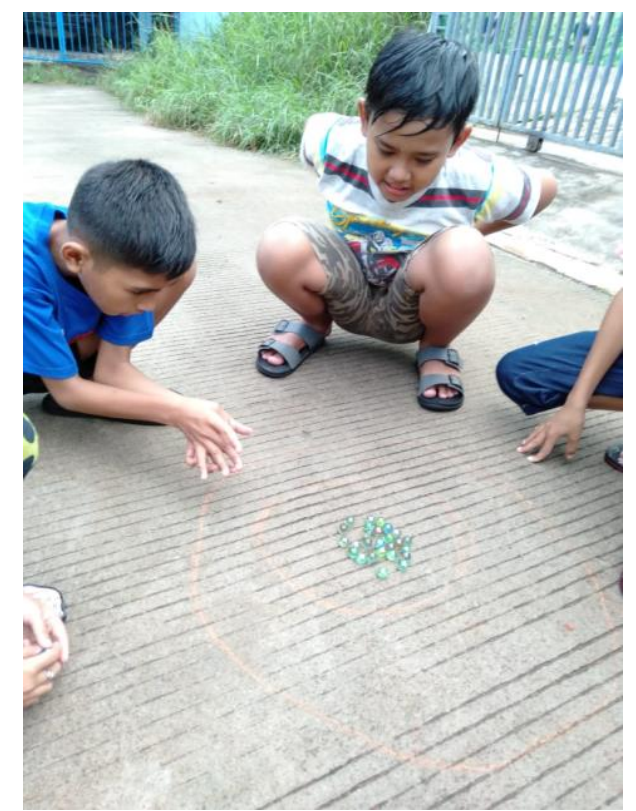

Gambar 4. Anak Sedang Melakukan "Menyentil” Gacoan ke Kelereng Pasangan secara Bergantian

Adapun langkah-langkah bermain kelereng, sebagai berikut: (1) gambar lingkaran kecil di tanah, kemudian semua anak menaruh lima butir kelereng di dalam lingkaran atau tergantung dari kesepakatan para pemain; (2) semua anak berdiri kira-kira satu meter dari lingkaran, di belakang sebuah garis. Secara 
bergantian, lemparkan sebutir kelereng lainnya ke arah lingkaran. Anak yang kelerengnya paling jauh dari lingkaran, boleh main terlebih dahulu. Peraturan dalam memainkan permain ini yaitu pada intinya tergantung dari pemain (Hasanah, 2016); (3) anak harus memakai kelereng yang ada di luar lingkaran sebagai "Penyerang" agar kelereng di dalam lingkaran keluar. Jika berhasil melakukannya, maka anak boleh menyimpan setiap kelereng yang kena jentik; (4) pertemukan ibu jari dengan jari tengah, kemudian menyentil kedua jari tepat pada gundu, (5) kelereng penyerang harus tetap tinggal di dalam lingkaran. Jika tidak, maka anak yang memilikinya akan kehilangan kelereng tersebut, (6) pemenang adalah anak yang mengumpulkan kelereng atau gundu terbanyak, (7) jika sudah tidak ada lagi kelereng dalam lingkaran, ada kesempatan pemain mengenai kelereng pemain lain dengan masing-masing satu kesempatan, jika mengenai maka kelereng yang didapat oleh pemain yang terkena kelereng menyerahkan kelerengnya kepada pemain yang mengenai dan permainan telah selesai.

Etnomatematika yang terlihat dalam tahapan persiapan permainan dan tata cara permainan ini antara lain yaitu berupa konsep matematika berupa bangun ruang, bangun datar, dan pengukuran. Konsep matematika yang digunakan dalam permainan ini adalah ketika pemain menentukan urutan permainan dengan melakukan perbandingan atau pengukuran jarak terdekat dari suatu lubang (Indriani \& Imanuel, 2018). Pada saat persiapan ini, terlihat bahwa anak dalam bermain kelereng melakukan pengukuran dengan menggunakan jengkal. Selain itu, untuk menentukan siapa yang boleh terlebih dahulu memulai permainan ditentukan berdasarkan kelereng yang paling jauh jaraknya dengan kelereng pusat lingkaran. Hal tersebut dapat terlihat bahwa anak-anak sudah dapat menentukan jarak mana yang lebih jauh dan dekat dengan melakukan pengukuran.

Pola yang terdapat pada permainan kelereng memuat pola geometri dan kedua permainan ini dapat dimainkan lebih dari satu siswa (Sirate, 2015), artinya dalam permainan kelereng terdapat karakter siswa dalam melakukan kerja sama dan kebersamaan dalam permainan, serta dapat melatih kejujuran agar permainan menjadi sportif. Selain itu, permainan ini juga membuat siswa dapat membedakan bilangan ganjil dan berhitung dalam permainan kelereng. Manfaat moral dari permainan kelereng adalah anak dilatih untuk jujur jika berhasil menembak kelereng atau tidak. Manfaat sosial emosionalnya adalah kepercayaan diri meningkat karena kemauan mereka akan berkompetisi, anak mampu mengatur emosinya agar lebih fokus pada sasaran mereka, kesabaran 
dalam bermain membuat anak tidak gegabah dalam mengambil keputusan, melatih keterampilan sosial, dan sikap kepedulian dengan temannya, dan anak bersosialisasi dengan melakukan permainan ini bersama dengan teman secara adil. Manfaat gerak motoriknya adalah melatih keterampilan motorik halus anak (Khosasi, Damajanti, \& Muljosumarto, 2018). Keterampilan sosial yang muncul dalam permainan ini adalah anak menjadi lebih terampil dalam melakukan gerak motorik halus berupa menggenggam kelereng dan menjentikkan jarinya dalam melakukan permainan kelereng. Proses ini akan menjadikan anak menjadi lebih konsentrasi dalam melakukan permainan.

Terdapat bentuk-bentuk hasil budaya masyarakat yang memuat konsep matematika dan dibangun menjadi sebuah pendekatan dalam pembelajaran, disebut sebagai pembelajaran berbasis budaya. Tentu saja setiap bentuk etnomatematika disesuaikan dengan konsep matematika yang sepadan dan tidak menghambat peserta didik dalam mempelajari matematika. Oleh karena itu, pembelajaran perlu dikemas sebaik mungkin (Abi, 2016). Berdasarkan hal tersebut maka dapat diketahui bahwa dalam budaya permainan kelereng terdapat begitu banyak manfaat baik dari segi motorik dan kognitif bagi anakanak. Proses kegiatan permainan yang dilakukan dalam permainan kelereng juga menjunjung tinggi karakter siswa berupa kebersamaan, saling menghormati, menghargai, dan memberikan kesempatan kepada teman-teman dan menjunjung tinggi sportivitas bagi para pemain.

\section{SIMPULAN}

The culture is very important is embedded in students early on. Learning math based on culture can become a solution to introduce the culture and learning math (Maryati \& Prahmana, 2018). Permainan kelereng dapat melatih keterampilan motorik, melatih kemampuan berpikir (kognitif), kemampuan berhitung, mengasah keterampilan sosial, dan melatih anak mengendalikan emosi. Karena begitu banyak manfaat permainan ini hendaknya dapat terus dilestarikan dan dapat dijadikan sebagai salah satu media pembelajaran matematika bagi siswa sekolah dasar. Ada beberapa materi dalam pembelajaran matematika yang dapat menggunakan kelereng dan permainannya sebagai media pembelajaran yaitu adalah geometri, yakni bola merupakan salah satu bangun ruang yang bentuknya seperti kelereng. Selain itu, bangun datar berupa lingkaran yang digunakan di tengah untuk menampung kelereng pasangan, termasuk membilang, operasi hitung menggunakan kelereng. 


\section{DAFTAR PUSTAKA}

Abi, A. M. (2016). Integrasi etnomatematika dalam kurikulum matematika sekolah. Jurnal Pendidikan Matematika Indonesia, 1(1), 1-6.

Arindiono, R. Y., \& Ramaadhani, N. (2013). Perancangan media pembelajaran interaktif matematika untuk siswa kelas 5 SD Rudi. Jurnal Sains Dan Seni Pomits, 2(1), 28-32.

Hasanah, U. (2016). Pengembangan kemampuan fisik motorik melalui permaninan tradisional bagi anak usia dini. Al-Athfal: Jurnal Pendidikan Anak, 2(1), 115-134.

Indriani, M. N., \& Imanuel. (2018). Pembelajaran matematika realistik dalam permainan edukasi berbasis keunggulan lokal untuk membangun komunikasi matematis. Prisma (Prosidimg Seminar Nasional Matematika (Vol. 1, pp. 256-262).

Khosasi, L., Damajanti, M. N., \& Muljosumarto, C. (2018). Perancangan media pengenalan permainan tradisional untuk mendukung tumbuh kembang anak usia 6-9 tahun. Jurnal DKV Adiwarna, 1(12), 1-8.

Maryati \& Prahmana, R. C. I. (2018). Ethnomathematics: Exploring the activities of designing kebaya kartini. MaPan : Jurnal Matematika dan Pembelajaran, 6(1), 11-19.

Nkopodi, N., \& Mosimege, M. (2009). Incorporating the indigenous game of morabaraba in the learning of mathematics. South African Journal of Education, 29(2005), 377-392.

Risdiyanti, \& Prahmana, R. C. I. (2017). Ethnomathematics: Exploration in Javanese culture. Journal of Physics: Conference Series (pp. 1-6).

Saputra, N. E., \& Ekawati, Y. N. (2017). Permainan tradisional sebagai upaya meningkatkabn kemampuan dasar anak. Jurnal Psikologi Jambi, 2(2), 4853.

Sirate, S. F. S. (2015). Menggagas integrasi multikultural pembelajaran matematika. Auladuna, 2(2), 246-263.

Supriadi, Srisetyawan, A., \& Tiurlina. (2016). Mengintegrasikan pembelajaran matematika berbasis budaya banten pada pendirian sd laboratorium UPI kampus Serang. Mimbar Sekolah Dasar, 3(1), 1-18. https:/ / doi.org/10.17509/mimbar-sd.v3i1.2510

Tandililing, E. (2013). Pengembangan pembelajaran matematika sekolah dengan pendekatan etnomatematika berbasis budaya lokal sebagai upaya untuk meningkatkan kualitas pembelajaran matematika di sekolah. In Prosiding (pp. 978-979). 